\title{
Solvation of Electrosprayed Ions in the Accumulation/Collision Hexapole of a Hybrid Q-FTMS
}

\author{
Khadijeh Rajabi, ${ }^{a}$ Michael L. Easterling, ${ }^{\mathrm{b}}$ and Travis D. Fridgen ${ }^{\mathrm{a}}$ \\ a Department of Chemistry, Memorial University of Newfoundland, St. John's, Newfoundland, Canada \\ ${ }^{\mathrm{b}}$ Bruker Daltonics Inc., Billerica, Massachusetts, USA
}

In an effort to spectroscopically determine the structures of solvated ions composed of nucleic acid bases and amino acids, methods for their gas-phase synthesis have been studied. Ions were electrosprayed and solvated in the accumulation cell of a hybrid Q-FTICR filled with methanol or water vapor at $\sim 10^{-2}$ bar. There were subsequently transferred to the FTICR cell at $10^{-10}$ mbar. Following their isolation in the FTICR, they can be investigated by studying their unimolecular blackbody infrared radiative dissociation (BIRD) or infrared multiple photon dissociation (IRMPD) spectroscopy. The IRMPD spectra for (Ade) ${ }_{2} \mathrm{Li}^{+}$and (Ade) ${ }_{2} \mathrm{Li}\left(\mathrm{H}_{2} \mathrm{O}\right)^{+}$are reported and compared as well as BIRD rate constants for multiply solvated and metalated adenine ions. (J Am Soc Mass Spectrom 2009, 20, 411-418) (c) 2009 Published by Elsevier Inc. on behalf of American Society for Mass Spectrometry

\begin{abstract}
$\bigcirc$ tudies of solvated ions in the gas phase provide information about the preferred coordination of ions by solvent molecules and their conformational geometries and changes of geometry upon solvation [1]. The structural properties are typically deduced from fundamental studies of their thermochemistries, reactivities, and more recently, the vibrational spectroscopy of gaseous ions [2]. The ultimate purpose and challenge for studying the physical properties of sequentially solvated ions is to extrapolate to, or contrast these properties with, those in the solution phase especially for biologically interesting ions. Mass spectrometry has become a powerful technique for investigating biomolecules following the development of electrospray ionization (ESI) [3] and matrix-assisted laser desorption/ionization (MALDI) [4-6]. Noncovalently bound biological complexes can be transferred from aqueous solutions to the gas phase by ESI for further study of the completely desolvated complex. In some instances a small amount of solvated ions have been reported from electrospray allowing the structure, reactivity and thermochemistry of the hydrated ions to be studied [7]. Lee et al. [8] studied extensively hydrated peptides from an electrospray source by operating the capillary at room-temperature, with no nebulizer or drying gas, and optimizing the potentials in the electrospray source. These ions were found to be cooled to between 130 and $150 \mathrm{~K}$ by evaporation of water without drying gas, effectively freezing the biomolecules. RodriguezCruz et al. [9] studied doubly protonated gramicidin S
\end{abstract}

Address reprint requests to Dr. T. D. Fridgen, Department of Chemistry, Memorial University of Newfoundland, St. John's, NL, Canada A1B 3X7. E-mail: tfridgen@mun.ca ions with up to 50 water molecules attached in a modified instrument with a home-built electrospray source equipped with a heated capillary inlet. They formed the ions under "gentle" electrospray conditions and later described two possible mechanisms for formation of hydrated ions by ESI [10], condensation of solvent onto ions due to expansion inside the ESI interface, and/or solvent evaporation of more extensively hydrated ions or electrospray droplets. The extent of hydration of gas-phase gramicidin $\mathrm{S}(\mathrm{M}+2 \mathrm{H})^{2+}$ ions was observed to decrease with an increase in the temperature of the capillary.

Rodriguez-Cruz and Williams [11] also studied solvent exchange reactions of hydrated divalent alkaline earth metals with benzene by ESI Fourier-Transform mass spectrometry (FTMS) at room temperature. Aqueous solutions of metal chloride salts were introduced to the mass spectrometer by nanoelectrospray. Metal ions with 4-7 water molecules were selected and thermalized in the accumulation process by introducing $\mathrm{N}_{2}$ gas. After isolating the ions of interest, they were exposed to benzene at constant pressure. They showed that the rate constant of ligand exchange increases with the size of the metal due to the stronger cation- $\pi$ interaction between the metal ion and benzene. In addition, for the heptahydrated metal ions, the seventh water molecule was shown to be in an outer solvation shell, bound much more weakly, by observing the rates of unimolecular dissociation reactions losing subsequent water molecules. Recently, the structures of hydrated $\mathrm{Ca}^{2+}$ ions directly from an electrospray source have been studied by consequence spectroscopy [12] and thermochemically by collision-induced dissociation in a guided ion beam tandem mass spectrometer [13]. These
(C) 2009 Published by Elsevier Inc. on behalf of American Society for Mass Spectrometry. 1044-0305/09/\$32.00

doi:10.1016/j.jasms.2008.10.023
Published online November 11, 2008 Received June 27, 2008 Revised October 29, 2008 Accepted October 29, 2008 


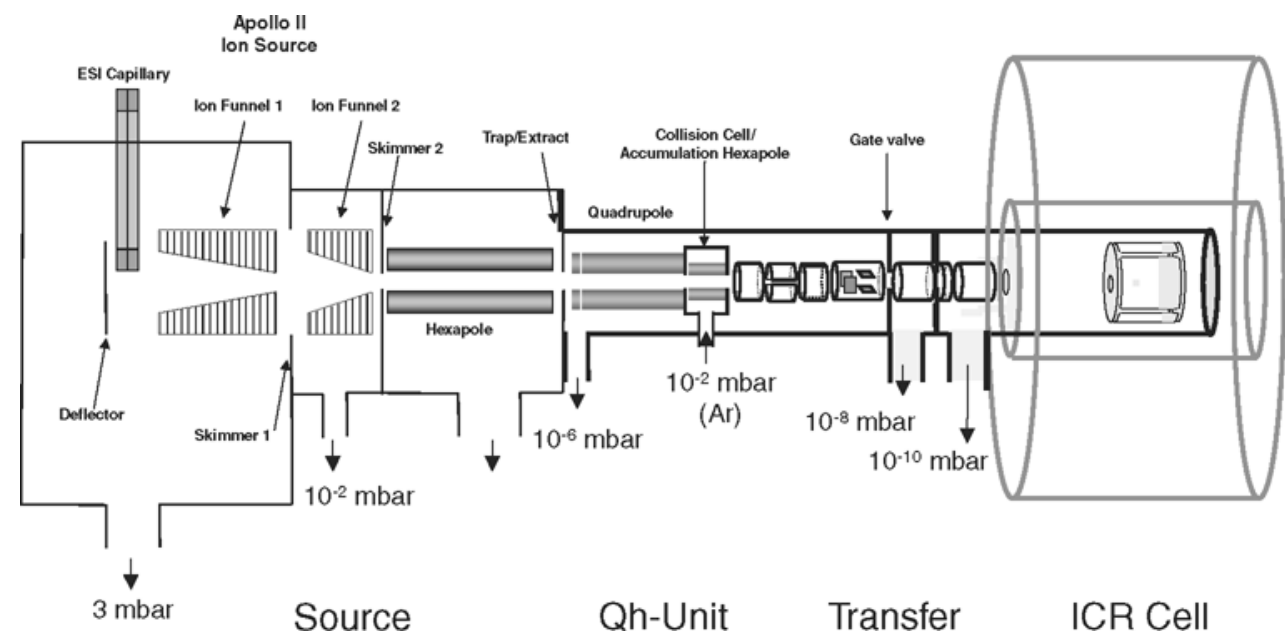

Figure 1. Schematic showing the source, Qh region, ion transfer optics, and ICR cell for the Bruker Apex Qe 70 FTMS.

studies show conclusively that the $\mathrm{Ca}^{2+}$ ion has six water molecules in the first solvent shell bound directly to the metal ion. While electrospray has been useful in the study of solvated ions, other methods of generating solvated gaseous ions included typically involve a high-pressure source of ions [14-19] or by injecting ions [20] or electrons [21, 22] into a molecular expansion.

Electrospray, under normal circumstances, is usually a very efficient method of forming completely desolvated gaseous ions. At Memorial University, we are interested in studying the structures and chemistry of ion-molecule complexes, such as protonated or metal ion-bound species, which are also solvated using techniques such as infrared multiple photon dissociation (IRMPD) spectroscopy, blackbody infrared radiative dissociation (BIRD) [23], and by ion/molecule reactions [24]. As a means to achieve this, a Bruker Apex Qe 70 FTMS has been obtained. As in any FTMS, due to the very low operating pressure of the ion cyclotron resonance (ICR) cell solvated species must be prepared outside the ICR cell. The purpose of this paper is to explain the method of solvating ions in the storage hexapole cell of a commercial hybrid Q-FTMS. We also present results of some preliminary studies of various solvated ions.

\section{Experimental}

For this work, three different Bruker Apex-Qe 70 FTMS instruments were used. The first is at the Bruker showroom in Billerica, MA, one is at the University of Paris 11 in Orsay, France, and the third is at Memorial University in St. John's, NL. The instrument in Orsay currently is mated to both a free electron laser and a Laser Vision OPO/OPA laser. Details of IRMPD experiments with both lasers have been published previously [25]. The IRMPD spectrum reported here was recorded using the OPO/OPA laser operating in the 2500-4000 $\mathrm{cm}^{-1}$ region covering the $\mathrm{N}-\mathrm{H}$ and $\mathrm{O}-\mathrm{H}$ stretching vibrations. If the laser is resonant with an infrared absorption then dissociation of the ion is observed. The spectral width of the laser was estimated to be $5 \mathrm{~cm}^{-1}$.

A schematic of the source, quadrupole/hexapole, ion transfer optics, and ICR cell region is shown in Figure 1. In normal electrospray ionization mode, a small amount of Ar gas (0.1-0.2 Lpm) flows into the collision hexapole to aid in trapping of ions and can be used to affect collision induced dissociation (CID). The pressure in the vacuum chamber around the collision cell is $\sim 10^{-5}$ mbar when Ar or solvent is flowing into the collision hexapole where the pressure is estimated to be $\sim 10^{-3}$ to $10^{-2}$ mbar. Ions are typically accumulated in the collision cell hexapole for a brief period of time, 100-500 ms but to prepare solvated species, higher accumulation times are desirable to increase the signal intensity. Following accumulation, the ions are transferred from this hexapole through a series of ion optics to the ICR cell. The instrument at Memorial University has been modified to include a second leak valve to introduce solvent into the quadrupole and hexapole region. While this adds flexibility and ease of use, experiments on the Billerica and Orsay instruments were conducted by simply replacing the Ar collision gas with a solvent sample, methanol, or water in the present experiments, in a glass vial. However, as noted below, if one prefers less solvation, the addition of a small pressure of solvent and some Ar to increase trapping efficiency makes at least two gas inlets desirable. The solvents were freeze-pump-thawed to expel dissolved air.

Precursor ions were electrosprayed from aqueous solutions containing $0.1 \mathrm{mM}$ adenine or thymine, and a few drops of $1 \mathrm{mM} \mathrm{LiCl}, \mathrm{KCl}$ or $\mathrm{CuSO}_{4}$ in $18 \mathrm{M} \Omega$ Millipore water (Billerica, MA). The DNA bases and salts were obtained from Aldrich (Oakville, ON, Canada) and were used without further purification. The water used to provide vapor for solvating was $18 \mathrm{M} \Omega$. 
The methanol used was $99.8 \%$ and was purchased from ACP Chemicals in Montreal.

\section{Results and Discussion}

The conditions in the accumulation cell play a crucial role in successful addition of solvent. Ion kinetic energy is expected to and does play a fairly important role in whether solvation occurs. In this instrumental configuration (Figure 1), the ion kinetic energy at the point of entry to the collision cell is programmed by how the collision cell is biased to the second stage of the ion funnel. Lowering the relative DC bias of the collision cell increases the kinetic energy over what is necessary to efficiently deliver the ions into the hexapole trap, effectively the "zero volt" collision energy. For these experiments, the effect of kinetic energy on solvation was explored by modulation of the collision cell DC bias. Zero to a few tenths of volts of collision energy has very little effect on solvation but more than a few volts results in inefficient solvation. As well, high collision voltages typically result in less cluster ions making it to the ICR cell. In Figure 2a, the effect of collision voltage is shown on the fraction of solvated (Thy) ${ }_{2} \mathrm{Li}^{+}$, defined as the intensity of $(\text { Thy })_{2} \mathrm{Li}^{+}\left(\mathrm{H}_{2} \mathrm{O}\right)$ divided by the sum of $(\text { Thy })_{2} \mathrm{Li}^{+}\left(\mathrm{H}_{2} \mathrm{O}\right)$ and (Thy $)_{2} \mathrm{Li}^{+}$intensities. After a few
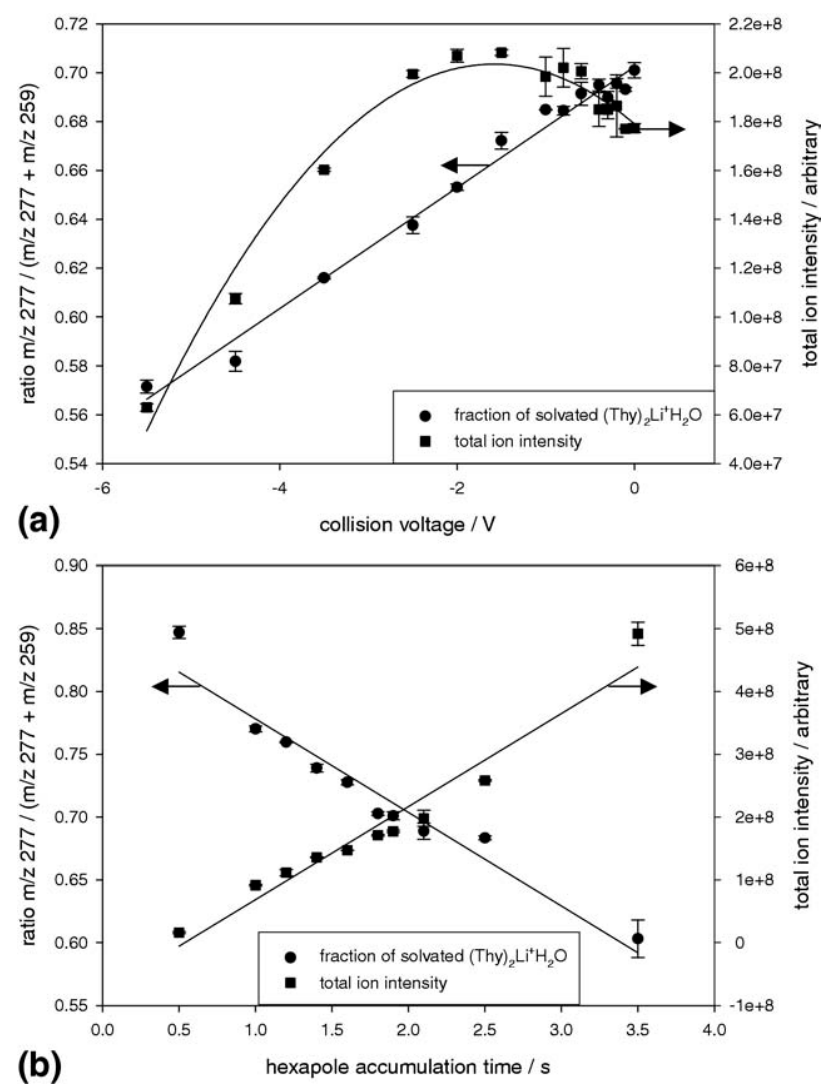

Figure 2. The fraction of solvated $\mathrm{Thy}_{2} \mathrm{Li}^{+}$and total ion intensity versus (a) collision voltage and (b) hexapole accumulation time. The "fitted" lines are merely to guide the eye. Arrows indicate the ordinate to which the data belong. tenths of a volt collision energy the fraction of solvated ions drops off fairly linearly. The total ion intensity (only (Thy) ${ }_{2} \mathrm{Li}^{+}$and its solvated analogue) is also plotted. The total ion intensity increases slightly from 0 to $\sim 2 \mathrm{~V}$, then drops off markedly. Typically we use 0 or very close to it, but not more than $1 \mathrm{~V}$ collision energy for IRMPD experiments.

The trapping time in the accumulation cell is also an important parameter. Shorter times typically result in a larger degree of solvation but also less total ion signal. There are instances, however, when total ion signal remains high, but a shorter time results in a stronger signal for solvated ions, and this parameter must be optimized for each system. For experiments such as IRMPD spectroscopy where hundreds of steps in wavelength are required with four to eight scans per wavelength, shorter times are beneficial. For solvation of (Thy) $)_{2} \mathrm{Li}^{+}$, Figure $2 \mathrm{~b}$ shows the effect of accumulation time on both the fraction of solvation and the total ion intensity. Typically $\sim 2 \mathrm{~s}$ is a good balance between a decent degree of solvation, good ion intensity, and total experiment time. The loss of solvated ion signal at longer times is most likely due to heating of ions in the hexapole trap. Sannes-Lowery et al. $[26,27]$ have reported that excessive storage times, more than a few seconds, can cause dissociation in biomolecules with low dissociation thresholds, termed multipole storage assisted dissociation (MSAD).

The pressure of solvent also must be optimized. If the solvent pressure is too high, the signal starts to fall off because the accumulation cell is filled with the solvent vapor, presumably resulting in loss of ions from the accumulation cell due to collisions. Typically, the pressure read on the ion gauge is $5-6 \times 10^{-5} \mathrm{mbar}$.

In addition, the chemical characteristic of the species is also important. For example, the basicity of the DNA bases can influence the ease and extent of solvation. It was found that it was easier to solvate ions containing uracil and thymine than adenine. Presumably this is because uracil and thymine are less basic than adenine [28]. The charge in cationized adenine is more diffuse, which may impede solvation. Furthermore, in our experience, solvation occurs at the "ionic centre" or the metal cation. As such stearic considerations and the size of the metal ion can affect solvation. While it is possible to attach many solvent molecules to potassiated bases, lithiated bases are difficult to multiply solvate. Furthermore, while it was possible to attach two water molecules to (Thy) $\mathrm{Li}^{+}$, we were only able to add one water molecule to (Thy) ${ }_{2} \mathrm{Li}^{+}$. Due to the different chemical nature of each ionic species, one set of conditions to prepare a particular ion with a given degree of solvation may not work for another ion. However, limited solvation in the accumulation cell seems to be efficient and highly reproducible once the right conditions are found.

One example, which illustrates how the chemical nature or structure of the precursor ion can affect solvation, is displayed in Figure 3. A small amount of 


\section{$\left[\mathrm{Cu}(\mathrm{Thy})_{2}-\mathrm{H}\right]^{+}$}

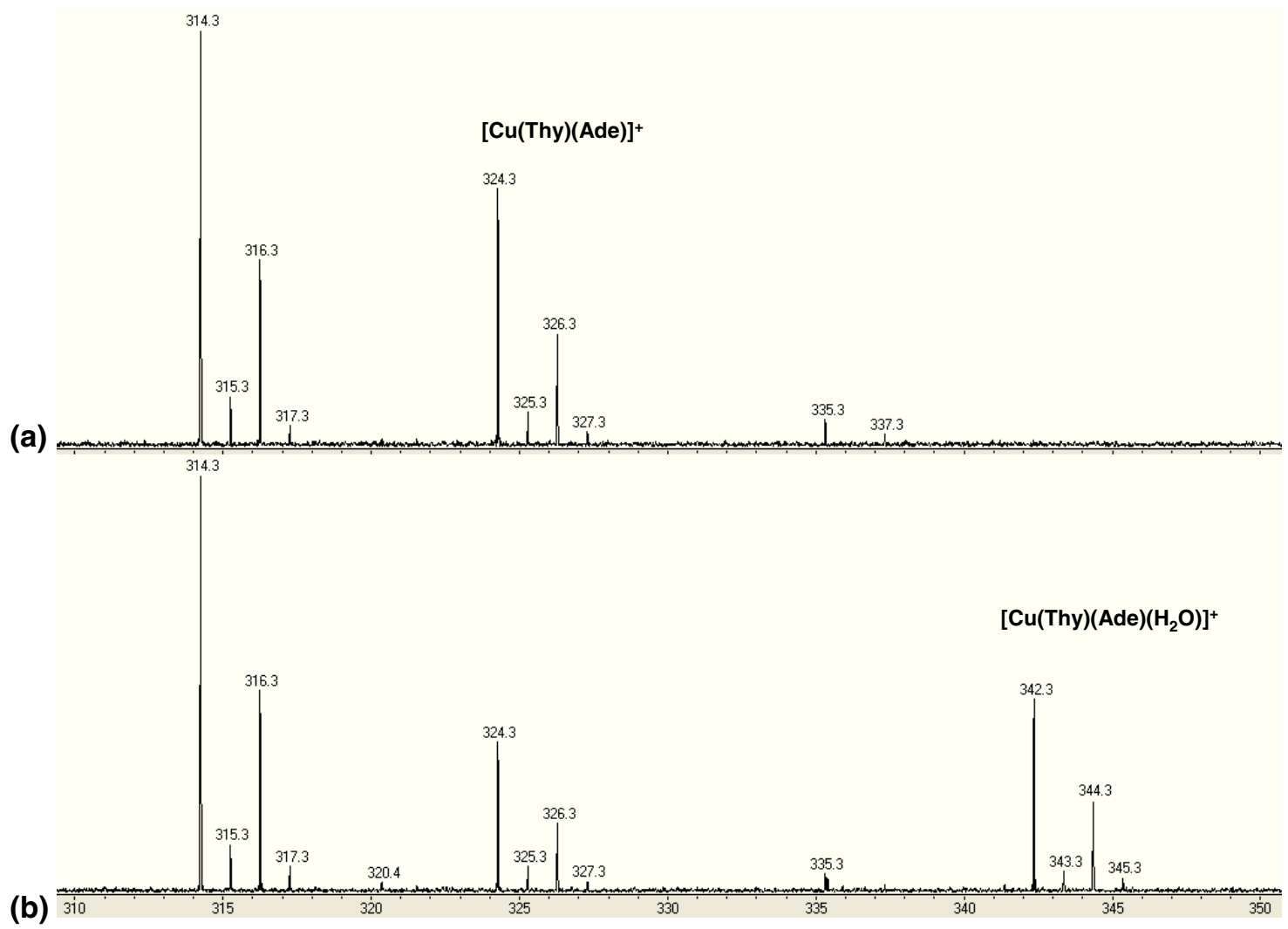

Figure 3. (a) ESI mass spectra of a $0.1 \mathrm{mM} \mathrm{CuCl}_{2}$ solution containing $\sim 0.1 \mathrm{mM}$ thymine and a few drops of $0.1 \mathrm{mM}$ adenine in $18 \mathrm{M} \Omega$ water. (b) Same experiment except with water vapor in the hexapole accumulation cell.

adenine solution was also added to the thymine $/ \mathrm{CuSO}_{4}$ solution and it was possible to observe two ions containing copper. The first, whose main isotopic mass is at $\mathrm{m} / \mathrm{z} 314$ is $\left[\mathrm{Cu}(\mathrm{Thy})_{2}-\mathrm{H}\right]^{+}$and the second at $m / z 324$ is $[\mathrm{Cu} \text { (Thy)(Ade) }]^{+}$. At this point, it is uncertain as to why the former loses $\mathrm{H}^{+}$to remain singly charged, while the ion containing adenine is reduced by an electron. However, what is also interesting is that under no condition was it possible to solvate the $\mathrm{m} / \mathrm{z} 314$ ion while the $\mathrm{m} / \mathrm{z}$ 324 ion adds one molecule of water to form $\mathrm{m} / \mathrm{z} 342$. The $[\mathrm{Cu} \text { (Thy)(Ade) }]^{+}$ion also seemed to be maximized by spending $1.5 \mathrm{~s}$ time in the accumulation cell. The mass spectrum shown in Figure $3 \mathrm{~b}$ is after $1.5 \mathrm{~s}$ in the accumulation cell, while longer storage times resulted in less $\mathrm{m} / \mathrm{z} 342$ and more $\mathrm{m} / \mathrm{z} 324$ but overall less ion intensity. The ability of $\mathrm{m} / \mathrm{z} 324$ to add water and the inability of $\mathrm{m} / \mathrm{z} 314$ to add water could be due to the difference in binding energy of water to these ions and/or major structural differences. For example, the structure of $\mathrm{m} / \mathrm{z} 314$ ion could limit access of solvent to the "central" copper ion. This is a question for further study using spectroscopic, thermochemical, and computational techniques.

In Figure 4 BIRD plots are presented for solvated potassium cation bound dimers of adenine, (Ade) ${ }_{2} \mathrm{~K}^{+}$, with up to three solvent molecules of either water
(Figure 4a) or methanol (Figure 4b). While it was possible to add three water molecules to (Ade) ${ }_{2} \mathrm{~K}^{+}$, it was not possible to obtain much more than $15 \%$ of the total ion abundance of $(\text { Ade })_{2}\left(\mathrm{H}_{2} \mathrm{O}\right)_{n} \mathrm{~K}^{+}$. Based on its instability in the ICR cell, this is likely due to a small binding energy for the third water molecule. For methanol, a good abundance of triply solvated ion, $\sim 70 \%$ of the total solvated ion intensity was obtained. BIRD rate constants were derived from this data by modeling the intensity versus time data assuming a sequential loss of solvent dissociation mechanism, $\left(\mathrm{X}=\mathrm{H}_{2} \mathrm{O}, \mathrm{CH}_{3} \mathrm{OH}\right)$

$$
\begin{aligned}
& (\text { Ade })_{2}(\mathrm{X})_{3} \mathrm{~K}^{+} \stackrel{\mathrm{k}_{3-2}}{\longrightarrow}(\text { Ade })_{2}(\mathrm{X})_{2} \mathrm{~K}^{+}+\mathrm{X} \\
& (\text { Ade })_{2}(\mathrm{X})_{2} \mathrm{~K}^{+} \stackrel{\mathrm{k}_{2-1}}{\longrightarrow}(\text { Ade })_{2}(\mathrm{X}) \mathrm{K}^{+}+\mathrm{X} \\
& (\text { Ade })_{2}(\mathrm{X}) \mathrm{K}^{+} \stackrel{\mathrm{k}_{1-0}}{\longrightarrow}(\text { Ade })_{2} \mathrm{~K}^{+}+\mathrm{X}
\end{aligned}
$$

which, based on the fits to the data, is a good assumption.

In all cases, BIRD rate constants for loss of water are significantly larger than for loss of methanol (see Table 1). A temperature study is required to obtain binding energies [29] for sequential solvent loss, however, it is safe to make a few qualitative remarks. BIRD rates are mainly 

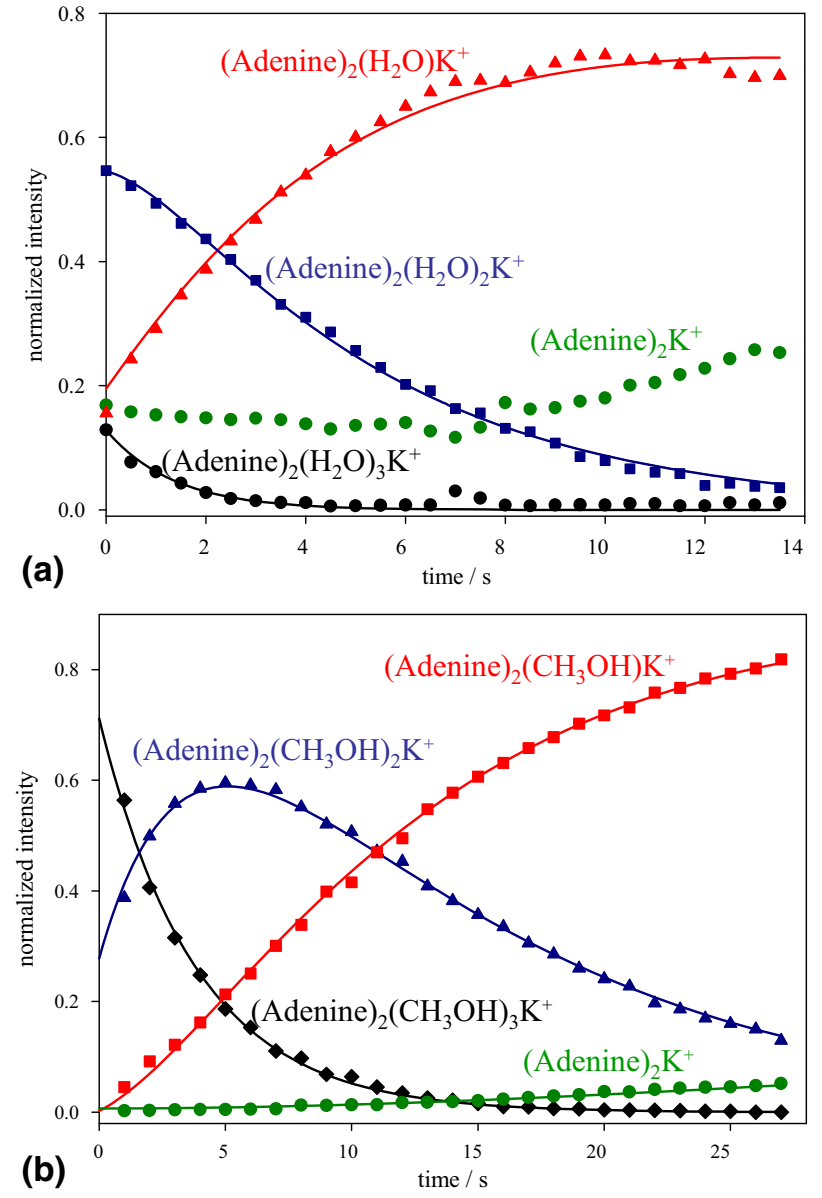

Figure 4. BIRD plots for sequential loss of solvent from (Ade) ${ }_{2}(\mathrm{X})_{3} \mathrm{~K}^{+}$, ((a) $\mathrm{X}=\mathrm{H}_{2} \mathrm{O}$, (b) $\mathrm{X}=\mathrm{CH}_{3} \mathrm{OH}$ ). Rate constants for sequential solvent loss are in Table 1.

dependent upon the binding energy of the complex, but the rate of photon absorption is also important. Therefore, to compare methanol and water binding energies, one has to take into account the difference in absorption properties of water and methanol. The strongly absorbing $\mathrm{O}-\mathrm{H}$ symmetric stretch at higher energy are replaced by relatively weak $\mathrm{C}-\mathrm{H}$ stretching. The $\mathrm{HOH}$ bend is replaced by a strongly absorbing $\mathrm{CO}$ stretch and HOC bend (among other torsional modes). Based on the positions of these bands and the blackbody radiation curve, which is at a maximum at about $1000 \mathrm{~cm}^{-1}$, it is safe to say the methanol ligand is at least as strongly absorbing of blackbody radiation as a water ligand. Based on absorbing properties alone, the complexes solvated with methanol would probably be expected to have a larger BIRD rate constant than those solvated with water. That it has a smaller rate constant can only be attributed to a stronger binding energy for methanol to the central (Ade) ${ }_{2} \mathrm{~K}^{+}$.

Also in Table 1 are the BIRD rate constants obtained when (Ade) $)_{2}\left(\mathrm{H}_{2} \mathrm{O}\right)_{3} \mathrm{~K}^{+}$or (Ade) $)_{2}\left(\mathrm{H}_{2} \mathrm{O}\right)_{2} \mathrm{~K}^{+}$were isolated in the ICR cell using correlated harmonic excitation fields (CHEF) [30, 31]. It is not expected that the BIRD rate constants are affected by the isolation process. The BIRD rate constants for the (Ade) $)_{2}\left(\mathrm{H}_{2} \mathrm{O}\right)_{2 \rightarrow 1} \mathrm{~K}^{+}$reaction are 0.212 and $0.300 \mathrm{~s}^{-1}$ when $n=3$ or $n=2$ are isolated, respectively. These values are different due to the errors in modeling the multiple rate constants. When $n=3$ is isolated it is expected that the $n=2$ to $n=1$ rate constant is in greater error due to its dependence upon the $n=3$ to $n=2$ rate constant, which typically has at most a $10 \%$ error associated with it from the modeling. To obtain reliable rate constants it is necessary to isolate the ion of interest. The $0.300 \mathrm{~s}^{-1}$ rate constant for dissociation of $(\text { Ade })_{2}\left(\mathrm{H}_{2} \mathrm{O}\right)_{2}$ is expected to be more reliable.

The mass spectrum obtained by electrospraying a 0.1 $\mathrm{mM}$ adenine and a few drops of $1.0 \mathrm{mM} \mathrm{LiCl}$ solution followed by $2 \mathrm{~s}$ of accumulation of the lithium ion bound adenine dimer in the accumulation hexapole with $\sim 10^{-2}$ mbar background pressure of water is shown in Figure 5a. Both $m / z 277\left((\text { Ade })_{2} \mathrm{Li}^{+}\right)$and $m / z$ $295\left((\text { Ade })_{2} \mathrm{Li}\left(\mathrm{H}_{2} \mathrm{O}\right)^{+}\right)$are detected. Following absorption of the tunable optical parametric oscillator (OPO) laser tuned to $3350 \mathrm{~cm}^{-1}$ and focused into the ICR cell for $0.5 \mathrm{~s}$ loss of water is detected (Figure $5 \mathrm{~b}$ ).

These results have shown that solvating cluster ions are possible in the accumulation hexapole of a hybrid Q-FTMS. In Figure 6, the IRMPD spectra of both (Ade) $)_{2} \mathrm{Li}^{+}$and $(\text {Ade })_{2} \mathrm{Li}\left(\mathrm{H}_{2} \mathrm{O}\right)^{+}$are displayed along with the lowest energy computed structures and B3LYP $/ 6-31+G(d, p)$ predicted IR spectra. The details of the combination of the Bruker Apex Qe 7T Fourier transform ion cyclotron resonance mass spectrometer (FTICR-MS) with the Laser Vision infrared optical parametric oscillator/amplifier (OPO/OPA) in Orsay, France has been described previously. Briefly, the tunable OPO/OPA laser is scanned in frequency from about 2 to $4 \mu \mathrm{m}$ (or in the reverse direction). When the laser radiation is resonant with a vibrational mode, the ion absorbs a few photons until it is able to dissociate. Absorption, then, is detected by a decrease in the precursor ion intensity concurrently with an increase in fragment ion intensity. The IRMPD efficiency

Table 1. Summary of BIRD rate constants for solvent loss at $298 \mathrm{~K}$ for $(\text { Ade })_{2}\left(\mathrm{H}_{2} \mathrm{O}\right) \mathrm{K}^{+}$and $(\mathrm{Ade})_{2}\left(\mathrm{CH}_{3} \mathrm{OH}\right) \mathrm{K}^{+}$clusters

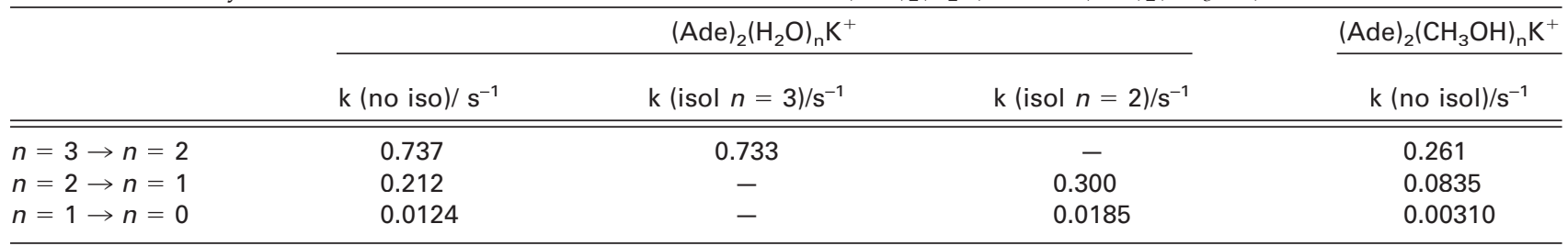



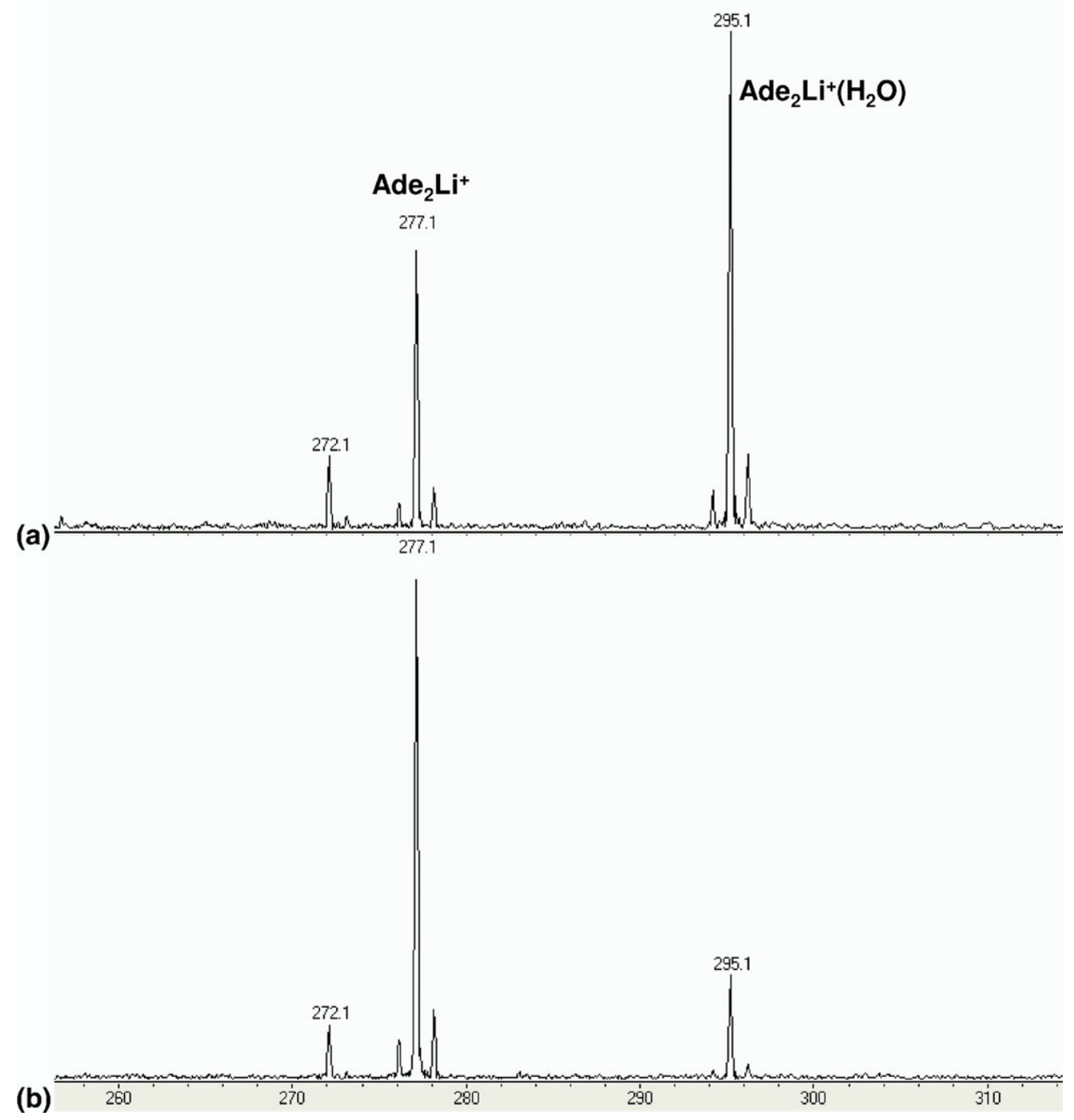

Figure 5. (a) ESI mass spectra showing the formation of $(\text { Ade })_{2} \mathrm{Li}\left(\mathrm{H}_{2} \mathrm{O}\right)^{+}$by reacting $(\mathrm{Ade})_{2} \mathrm{Li}^{+}$with water vapor in the accumulation hexapole. (b) Mass spectrum showing the effect of absorption of the OPO laser tuned to $3350 \mathrm{~cm}^{-1}$ for $0.5 \mathrm{~s}$.

is defined as the negative of the natural logarithm of the ratio of fragment ion intensities to the sum of the fragment and precursor ion intensities. While these spectra will be fully discussed along with those of other species in a forthcoming article, a brief discussion of the spectra will be given here. The IRMPD spectrum of (Ade) ${ }_{2} \mathrm{Li}^{+}$(bottom of Figure 6) is fairly simple with the two main features at 3435 and $3490 \mathrm{~cm}^{-1}$ assigned to the $\mathrm{NH}_{2}$ symmetric stretching vibrations and the $\mathrm{N}-\mathrm{H}$ stretch, respectively. There is also a weak feature centered at $3550 \mathrm{~cm}^{-1}$, corresponding to the $\mathrm{NH}_{2}$ asymmetric stretching modes. These band positions are clearly well reproduced by the B3LYP/6-31+G(d,p) theoretical predictions (scaled by 0.958 ). The addition of one water molecule to this structure provides a richer IRMPD spectrum (top spectrum in Figure 6). The $\mathrm{NH}_{2}$ symmetric stretching vibrations and the $\mathrm{N}-\mathrm{H}$ stretch at 3446 and $3504 \mathrm{~cm}^{-1}$, respectively, and the $\mathrm{NH}_{2}$ asymmetric stretch is observed at $3557 \mathrm{~cm}^{-1}$, in very similar positions as for the bare $\mathrm{Li}^{+}$-bound dimer of adenine discussed above. The new feature at $3724 \mathrm{~cm}^{-1}$ is assigned to water asymmetric $\mathrm{OH}$ stretching. The absence of a symmetric $\mathrm{OH}$ stretch for water, typically observed around $3650 \mathrm{~cm}^{-1}$, indicates that one of the $\mathrm{O}-\mathrm{H}$ bonds are involved in hydrogen bonding. The two broad bands centered at 3180 and $3360 \mathrm{~cm}^{-1}$ are typical of strongly hydrogen bonded, and therefore red-shifted, $\mathrm{O}-\mathrm{H}$ stretching vibrations. While there are many possible structures for the (Ade) ${ }_{2} \mathrm{Li}\left(\mathrm{H}_{2} \mathrm{O}\right)^{+}$ion, two that are the lowest in free-energy and differ by less than $1 \mathrm{~kJ}$ $\mathrm{mol}^{-1}(\mathrm{~B} 3 \mathrm{LYP} / 6-31+\mathrm{G}(\mathrm{d}, \mathrm{p}))$ that have been discovered are shown along with their predicted infrared spectra. The experimental and computed infrared spectra agree very well above $3400 \mathrm{~cm}^{-1}$. There is some disagreement between the experimental and predicted spectra for the two lower energy features, but this is to be expected 


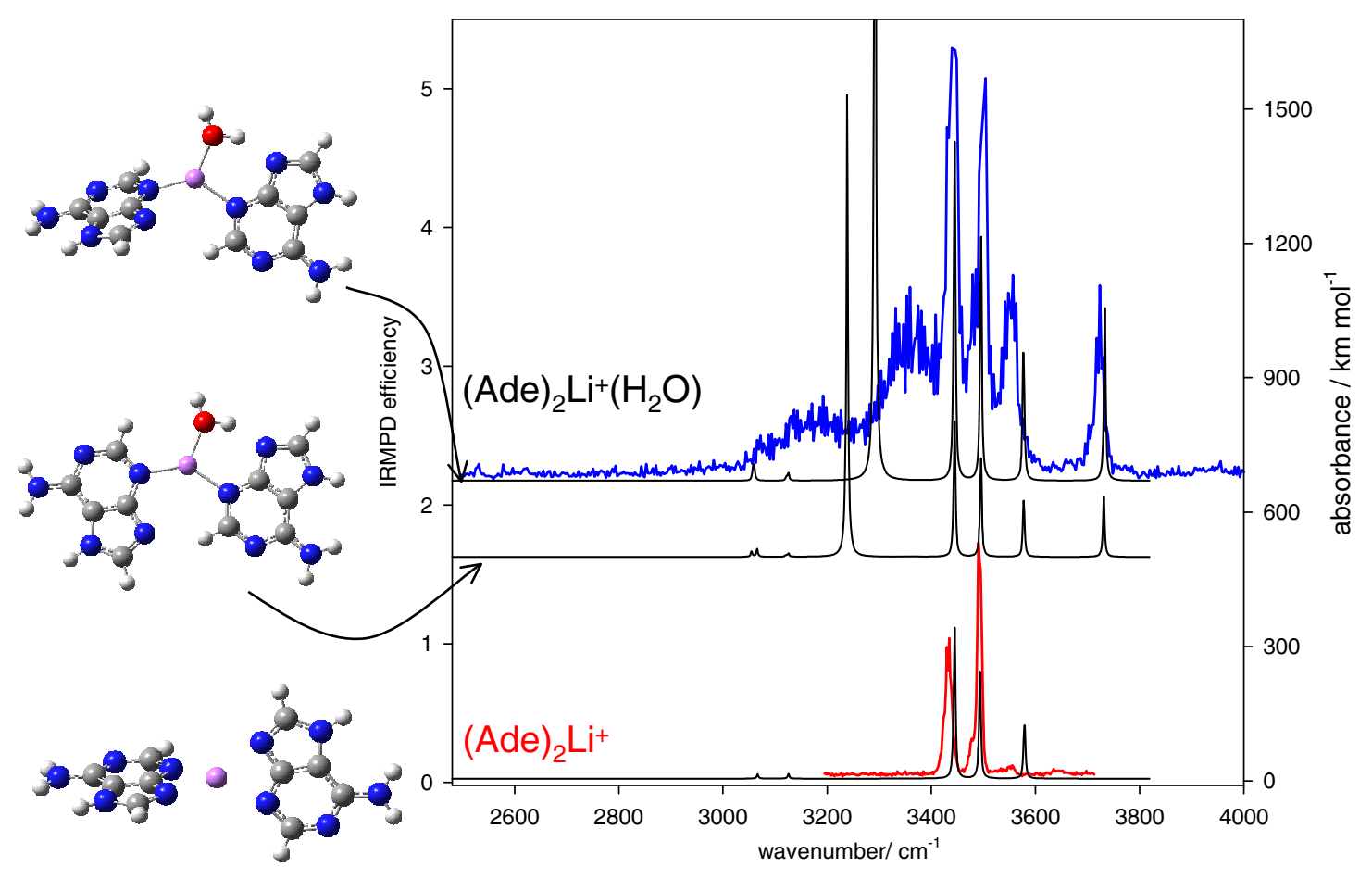

Figure 6. IRMPD spectra of (Ade) $)_{2} \mathrm{Li}$ and $(\mathrm{Ade})_{2} \mathrm{Li}\left(\mathrm{H}_{2} \mathrm{O}\right)^{+}$in $2500-4000 \mathrm{~cm}^{-1}$ region. Also shown are B3LYP $/ 6-31+G(d, p)$ computed structures and infrared spectra of the lowest energy structure for (Ade) $)_{2} \mathrm{Li}$ and two lowest energy structures for $(\text { Ade })_{2} \mathrm{Li}\left(\mathrm{H}_{2} \mathrm{O}\right)^{+}$.

for strongly anharmonic vibrations such as hydrogen bonded $\mathrm{O}-\mathrm{H}$ stretches. The important point with regard to the spectra is that the experimental spectra are consistent with structures such as those shown in Figure 6. Furthermore, when water is added to the adenine $\mathrm{Li}^{+}$-bound dimer in the hexapole, it adds to the $\mathrm{Li}^{+}$ion, which is the most thermodynamically stable position.

\section{Conclusions}

Evidence is provided for the efficient solvation of cations in the hexapole accumulation cell of a hybrid Q-FTMS. While the number of parameters to modify are numerous, our experience shows that the most sensitive parameters are the collision energy in the hexapole, pressure of both argon and solvent in the hexapole, accumulation time, and the chemical nature of the species. By solvating ions in the hexapole, it is possible to obtain very interesting physical data such as BIRD kinetics as well as IRMPD spectra, both of which can be used to determine structural information for the species under investigation.

\section{Acknowledgments}

The authors are grateful for the generous financial support of their work by the Natural Sciences and Engineering Research Council of Canada (NSERC). They gratefully acknowledge the financial support in the form of a Leaders Opportunity Fund Award from the Canadian Foundation for Innovation, the matching funding from the Industrial Research and Innovation Fund from the Province and Newfoundland and Labrador, as well as the substantial matching funding from Bruker. The financial support of the European Commission through EPITOPES is also gratefully acknowledged as is the technical assistance of T. Besson and P. Maitre. They acknowledge technical expertise of Christian Berg in assisting with some of the experiments in. They also greatly appreciate the thorough editing of the original manuscript by C.G. Atkins, E.A.L. Gillis, and M.B. Burt.

\section{References}

1. Desfrancois, C.; Carles, S.; Schermann, J. P. Weakly Bound Clusters of Biological Interest. Chem. Rev. 2000, 100, 3943-3962.

2. MacAleese, L.; Philippe, M. Infrared Spectroscopy of Organometallic Ions in the Gas Phase: From Model to Real World Complexes. Mass Spectrom. Rev. 2007, 26, 583-605.

3. Fenn, J. B.; Mann, M.; Meng, C. K.; Wong, S. F.; Whitehouse, C. M. Electrospray Ionization for Mass Spectrometry of Large Biomolecules. Science 1989, 246, 64-71.

4. Karas, M.; Hillenkamp, F. Laser Desorption Ionization of Proteins with Molecular Masses Exceeding 10,000 Daltons. Anal. Chem. 1988, 60, 2299-2301.

5. Tanaka, K.; Ido, Y.; Yoshida, Y.; Yoshida, T. Proceedings of the second Japan-China Joint Symposium on Mass Spectrometry; Osaka, Japan, September 1987.

6. Tanaka, K.; Waki, H.; Ido, Y.; Akita, S.; Yoshida, T. Protein and Polymer Analyse up to $m / z \quad 100,000$ by Laser Ionization Time-of-flight Mass Spectrometry. Rapid Commun. Mass Spectrom. 1988, 2, 151-153.

7. Klassen, J. S.; Blades, A. T.; Kebarle, P. Determinations of Ion-Molecule Equilibria Involving Ions Produced by Electrospray. Hydration of Protonated Amines, Diamines, and Small Peptides. J. Phys. Chem. 1995, 99, 15509-15517.

8. Lee, S.-W.; Freivogel, P.; Schindler, T.; Beauchamp, J. L. Freeze-Dried Biomolecules: FT-ICR Studies of the Specific Solvation of Functional Groups and Clathrate Formation Observed by the Slow Evaporation of Water from Hydrated Peptides and Model Compounds In the Gas Phase. J. Am. Chem. Soc. 1998, 120, 11758-11765.

9. Rodriguez-Cruz, S. E.; Klassen, J. S.; Williams, E. R. Hydration of Gas-Phase Gramicidin S $(\mathrm{M}+2 \mathrm{H})^{+2}$ Ions Formed by Electrospray: The 
Transition From Solution to Gas-Phase Structure. J. Am. Soc. Mass Spectrom. 1997, 8, 565-568.

10. Rodriguez-Cruz, S. E.; Klassen, J. S.; Williams, E. R. Hydration of Gas-Phase Ions Formed by Electrospray Ionization. J. Am. Soc. Mass Spectrom. 1999, 10, 958-968.

11. Rodriguez-Cruz, S. E.; Williams, E. R. Gas-Phase Reactions of Hydrated Alkaline Earth Metal Ions, $\mathrm{M}^{2+}\left(\mathrm{H}_{2} \mathrm{O}\right)_{n}(\mathrm{M}=\mathrm{Mg}, \mathrm{Ca}, \mathrm{Sr}, \mathrm{Ba}$ and $n=$ 4-7), with benzene. J. Am. Soc. Mass Spectrom. 2001, 12, 250-257.

12. Bush, M. F.; Saykally, R. J.; Williams, E. R. Hydration of the Calcium Dictation: Direct Evidence for Second Shell Formation from Infrared Spectroscopy. Chem. Phys. Chem. 2007, 8, 2245-2253.

13. Carl, D. R. Moision, R M. Armentrout, P. B. Binding Energies for the Inner Hydration Shells of $\mathrm{Ca}^{2+}$ : An Experimental and Theoretical Investigation of $\mathrm{Ca}^{2+}\left(\mathrm{H}_{2} \mathrm{O}\right)_{\times}$Complexes $(\mathrm{X}=5-9)$. Int. J. Mass Spectrom. 2007, 265, 308-325.

14. Bogdanov, B.; McMahon, T. B. Thermochemistry and Structures of Solvated $\mathrm{S}_{\mathrm{N}} 2$ Complexes and Transition States in the Gas Phase: Experiment and Theory. Int. J. Mass Spectrom. 2005, 241, 205-223.

15. Bogdanov, B.; Peschke, M.; Tonner, D. S.; Szulejko, J. E.; McMahon, T. B. Stepwise Solvation of Halides by Alcohol Molecules in the Gas Phase. Int. J. Mass Spectrom. 1999, 185/187, 707-725.

16. Chowdhury, S.; Grimsrud, E. P.; Kebarle, P. Bonding of Charge Delocalized Anions to Protic and Dipolar Aprotic Solvent Molecules. J. Phys. Chem. 1987, 91, 2551-2556.

17. Zhan, D.; Rosell, J.; Fenn, J. B. Solvation Studies of Electrospray Ions-Method and Early Results. J. Am. Soc. Mass Spectrom. 1998, 9, 1241.

18. Hiraoka, K.; Mizuse, S.; Yamabe, S. Solvation of Halide Ions with Water and Acetonitrile in the Gas Phase. J. Phys. Chem. 1988, 92, 3943-3952.

19. Yang, X.; Castleman, A. W. Production and Magic Numbers of Large Hydrated Anion Clusters X-(H2O)N $=0-59$ ( $\mathrm{X}=$ Hydroxyl, Oxygen Atom or Molecule, and Ozone) under Thermal Conditions. J. Phys. Chem. 1990, 94, 8500-8502.

20. Cabarcos, O. M.; Weinheimer, C. J.; Martinez, T. J.; Lisy, J. M. The Solvation of Chloride by Methanol-Surface Versus Interior Cluster Ion States. J. Chem. Phys. 1999, 110, 9516-9526.

21. Asmis, K. R.; Santambogio, G.; Zhou, J.; Garand, E.; Headrick, J.; Goebbert, D.; Johnson, M. A.; Neumark, D. M. Vibrational Spectroscopy of Hydrated Electron Clusters $(\mathrm{H} 2 \mathrm{O})^{-}{ }_{15-50}$ via Infrared Multiple Photon Dissociation. J. Chem. Phys. 2007, 126, 191105-1.
22. Roscioli, J. R.; Hammer, N. I.; Johnson, M. A.; Diri, K.; Jordan, K. D. Exploring the Correlation Between Network Structure and Electron Binding Energy in the $\left(\mathrm{H}_{2} \mathrm{O}\right)_{7}{ }^{-}$Cluster through Isomer-Photoselected Vibrational Predissociation Spectroscopy and Ab Initio Calculations: Addressing Complexity Beyond Types I-III. J. Chem. Phys. 2008, 128, 104314.

23. Dunbar, R. C. BIRD (Blackbody Infrared Radiative Dissociation): Evolution, Principles, and Applications. Mass Spectrom. Rev. 2004, 23, 127-158.

24. Brodbelt, J. S. Analytical Applications of Ion-Molecule Reactions. Mass Spectrom. Rev. 1997, 16, 91-110.

25. Bakker, J. M.; Besson, T.; Lemaire, J.; Scuderi, D.; Maitre, P. Gas-Phase Structure of a $\pi$-Allyl-Palladium Complex: Efficient Infrared Spectroscopy in a 7 T Fourier Transform Mass Spectrometer. J. Phys. Chem. A 2007, 111, 13415-13424.

26. Sannes-Lowery, K. A.; Hofstadler, S. A. Characterization of Multipole Storage Assisted Dissociation: Implications for Electrospray Ionization Mass Spectrometry Characterization of Biomolecules. J. Am. Soc. Mass Spectrom. 2008, 11, 1-9.

27. Sannes-Lowery, K. A.; Griffey, R. H.; Kruppa, G. H.; Speir, J. P.; Hofstadler, S. A. Multipole Storage Assisted Dissociation, A Novel In-Source Dissociation Technique for Electrospray Ionization Generated Ions. Rapid Commun. Mass Spectrom. 1998, 12, 1957-1961.

28. Hunter, E. P.; Lias, S. G. Evaluated Gas Phase Basicities and Proton Affinities of Molecules: An Update. J. Phys. Chem. Ref. Data 1998, 27, 413-656.

29. Schnier, P. D.; Price, W. D.; Jockusch, R. A.; Williams, E. R. Blackbody Infrared Radiative Dissociation of Bradykinin and Its Analogues: Energetics, Dynamics, and Evidence for Salt-Bridge Structures in the Gas Phase. J. Am. Chem. Soc. 1996, 118, 7178-7189.

30. Heck, A. J. R.; Koning, L. J.; Pinkse, F. A.; Nibbering, N. M. M. Mass-Specific Selection of Ions in Fourier-transform Ion Cyclotron Resonance Mass Spectrometry. Unintentional Off-Resonance Cyclotron Excitation of Selected Ions. Rapid Commun. Mass Spectrom. 1991, 5 , $406-414$.

31. de Koning, L. J.; Nibbering, N. M. M.; van Orden, S. L.; Laukien, F. H. Mass Selection of Ions in a Fourier Transform Ion Cyclotron Resonance Trap Using Correlated Harmonic Excitation Fields (CHEF). Int. J. Mass Spectrom. Ion Processes 1997, 165/166, 209-219. 